\title{
Conectivismo hermenéutico en la canción Yo Soy de Junín: Identidades hacia afuera
}

\author{
Hermeneutic connectivism in the song i am from Junín:Abstract: Identities outward \\ Carlos Luis Arauzo Gallardo*I \\ *Departamento Académico de Educación, Facultad de Educación, Universidad Nacional del Centro del Perú (UNCP), Huancayo-Perú.
}

\begin{abstract}
Resumen
El estudio conectivista hermenéutico de la canción Yo Soy de Junín es una investigación cualitativa de método hermenoeducativo. Se entrevistó a cuatro ciudadanos juninos identificados con el arte, cultura e investigación permanente, quienes interpretan la intención, el significado (atributos de nacimiento, historia, promiscuidad y galantería), la función (identificación, patriotismo, machismo y virilidad) y el condicionamiento socio ambiental (sentido de orgullo por el héroe Simón Bolívar y evolución de las canciones andinas) del autor de esta emblemática canción. Con el fin de interpretarla correctamente.
\end{abstract}

Palabras Claves: Junín, hermenoeducativo, educación, identidad, canción, análisis.

\begin{abstract}
The hermeneutic connectivist study of the song I am from Junin is a qualitative researchof hermeneuticmethod. Four Junin citizensidentified withart, culture andpermanent research were interviewed. They interpret the intention, meaning (attributes of birth, history, promiscuity and gallantry), function (identification, patriotism, machismo, virility) and socio-environmental conditioning (sense of pride in the hero Simón Bolívar and evolution of Andean songs) of the author of this emblematic song. In order tointerpret it correctly.
\end{abstract}

Keywords: Junín, hermenoeducational, education, identity, song, analysis.

1 Correspondiencia: Carlos Luis Arauzo Gallardo, carlosarauzog@gmail.com 


\section{Conectivismo hermenêutico na canção eu sou de Junín: Identidades para surgir}

\section{Resumo}

O estudo cognitivista hermenêutico da canção “Yo soy de Junín” (Eu sou Junin) é uma investigação qualitativa de métodos hermenêuticos. Se entrevistou a quatro cidadãos juninos identificados com a arte, cultura e investigação permanente, que interpretam a intenção, o significado (atributos de nascimento, história, promiscuidade e galanteria), a função (identificação, patriotismo, machismo, virilidade) e o condicionamento sócio ambiental (sentido de orgulho pelo herói Simon Bolívar e a evolução das canções andinas) do autor desta emblemática canção. Com a finalidade de interpretá-la corretamente.

Palavras Claves: Junín, hermenêuticos, educação, identidade, canção, análise.

\section{Conectivismum hermeneútico chay taki ñuham Juninmanta kani: Identinakuna awaman riy Uchuycha}

Yachayconectivistahermeneúticotakipa "ÑuqamJuninmanta kaki" kan huchayaytataripay cualitativa chay método hermenoeducativonisqan. Tawa juninos llaqtayuqkunariqsiqkuna Arteta,culturata, hucharaytataripay mana tukuriqta paykunaumanchansunqunta, yachanruwasqanta, imaynallankinrunakunapata, imaynammunanallpakausayqawariyta (harihariSimómBolivarkasqanmanta, chay andino takikuna) chay sumaqtakita Ruwasqaqta. Allintakinanchipaq.

Hatun apup simi: Junín, hermenoeducativo, edukasyun, riqsy, taki, kuskina. 


\section{Introducción}

El artículo presenta un análisis hermenéutico de la canción Yo Soy de Junín. Creada aproximadamente en el año 1930, el autor es el compositor Emilio Alanya Carhuamaca en medio de un periodo sumamente dificultoso económicamente por la crisis económica mundial y la polarización ideológica y política española (Alberto, 2011). De esta manera se quiere descubrir la esencia válida respetando la relación del autor y sus propias vivencias.

Por medio del método hermenoducativo como metodología de la investigación cualitativa, se interpreta la canción "Yo soy de Junín". Se interpreta la intención, significado, función y condicionamiento social - ambiental. Descubriendo el significado conjunto de toda expresión artística "Yo soy de Junín por vida" de la vida humana, de la región de Junín (Cerrón, 2019; Martínez, 2004). Para conocer la intención pedagógica.

\section{Yo soy de Junín por vida}

Yo soy de Junín por vida.

El Mantaro es mi valle,

Huancayo, Jauja, Oroya y Tarma son pueblos de mi Junín.

En Junín nació mi verso,

En Junín luchó Bolívar,

En esta tierra en donde se vive contento y muy feliz.

Ladroncito soy de amores,

No me importa amor de extraños.

Cuidado negra que yo me llevé robando tu corazón.

\section{Fuga}

Orgulloso vivo por eso porque mi terruño es Junín

En Junín se vive dichoso bajo el aire libre y puro.

De la entrevista realizada al profesor Alberto Castillo Huerta, se extrae, que el autor tuvo la intención pedagógica de educar en el patriotismo, en sus letras trasmite identidad a todo junino. Como se percibe en los siguientes versos:

Yo soy de Junín por vida, orgulloso vivo por eso porque mi terruño es Junín.

Por lo tanto, la canción expresa una manera de enseñar y aprender la identidad cultural provincial equivocada.

El significado pedagógico para el Perú y para todo el mundo de la Gloriosa Batalla de Junín, donde Luchó Bolívar, claro, no cuerpo a cuerpo como sus soldados, sino como quien dirigía todo un batallón de caballería, su sola presencia fue de mucha relevancia. Como se percibe en el siguiente verso: En Junín luchó Bolívar. Por lo tanto, la canción expresa una forma de enseñar y aprender un liderazgo inapropiado.

En cuanto a la función pedagógica, toda canción encierra algún mensaje, unas de decepción, otras de machismo, otras de mensaje que instigan a la violencia, a la venganza, como se percibe en los siguientes versos: No me importa amor de extraños. Cuidado negra que yo me llevé robando tu corazón. Por lo tanto, la canción expresa una forma de enseñar y aprender la carencia de respeto a las parejas formadas y al uso de la fuerza para obtener algo. 
Las condiciones pedagógicas en esa época, nacían en la escuela incentivada por los docentes. Como se percibe en los siguientes versos: Yo soy de Junín por vida, en Junín nació mi verso, orgulloso vivo por eso porque mi terruño es Junín, en esta tierra en donde se vive contento y muy feliz. Por lo tanto, la canción expresa la forma de enseñar y aprender la identidad cultural provincial, al conformismo y quedarse en su tierra y no salir en busca de oportunidades.

De la entrevista realizada al profesor Oblitas Cóndor Vásquez, se puede resumir que:

La intención pedagógica en la canción Yo soy de Junín es la de educar a sus ciudadanos y a todo peruano a amar a la tierra que lo vio nacer y ser agradecido. Como se percibe en los siguientes versos: Yo soy de Junín por vida, orgulloso vivo por eso porque mi terruño es Junín. Por lo tanto, la canción expresa una manera de enseñar y aprender la identidad cultural provincial no auténtica.

El significado pedagógico en la canción Yo soy de Junín, lo encontramos en sus letras algunas inconsistencias como: el hecho de nombrar a Huancayo, Jauja, Oroya y Tarma, como pueblos de Junín, dejando de lado a sus distritos Ulcumayo, Ondores, Carhuamayo y a Junín mismo. Como se aprecia en el siguiente verso: El Mantaro es mi valle, Huancayo, Jauja, Oroya y Tarma son pueblos de mi Junín. Por lo tanto, la canción expresa una manera de enseñar y aprender una irreal identidad provincial.

La función pedagógica que cumple la canción Yo soy de Junín, es la de difusión de identidad propiamente dicha, aun así, sus letras no encierran eso, pero el juninense la adoptó como suya, se enamoró de sus letras y siente bien así, como se percibe en el siguiente verso: El Mantaro es mi valle, Huancayo, Jauja, Oroya y Tarma son pueblos de mi Junín. Por lo tanto, la canción expresa una manera de enseñar y aprender la adopción.

Las condiciones pedagógicas en ese tiempo fueron muy limitadas, en la provincia de Junín no existía el nivel secundario, entonces muchos solo se quedaban con primaria incompleta y en poca escala con secundaria completa. Como se lee en el siguiente verso: En esta tierra en donde se vive contento y muy feliz, orgulloso vivo por eso porque mi terruño es Junín, en Junín se vive dichoso bajo el aire libre y puro. Por lo tanto, la canción expresa una manera de enseñar y aprender el conformismo.

De la entrevista al profesor Raúl Marín Güere Machacuay, se puede resumir que:

La intención pedagógica en la canción Yo soy de Junín, es de valorar y preservar la identidad. Como se percibe en los siguientes versos: Yo soy de Junín por vida, en Junín nació mi verso, orgulloso vivo por eso porque mi terruño es Junín. Por lo tanto, la canción expresa una manera de enseñar y aprender la identidad cultural provincial.

El significado pedagógico que podemos encontrar en la canción Yo soy de Junín, es de comprender hechos acontecidos en su pueblo a través de sus canciones. Como se expresa en los siguientes versos: En Junín luchó Bolívar, por lo tanto, la canción expresa una manera de enseñar y aprender la historia provincial.

La función pedagógica que cumple la canción Yo soy de Junín, es básicamente de formar un verdadero sentimiento al niño (a) hacia el fortalecimiento de su identidad, sentido de pertenencia y bienestar. Como se percibe en los siguientes versos: En esta tierra en donde se vive contento y muy feliz, orgulloso vivo por eso porque mi terruño es Junín. Por lo tanto, la canción expresa una manera de enseñar y aprender el sentido de pertenencia.

Las condiciones pedagógicas en la canción Yo soy de Junín, se ponen de manifiesto a través del arte y canto. Se tiene la condición de potenciar la creatividad y expresión libre en el educando para favorecer el desarrollo de habilidades propiamente artísticas y culturales. Como se percibe en el siguiente verso: En Junín nació mi verso. Por lo tanto, en la canción expresa una forma de enseñar y aprender la libre expresión a través del canto.

De la entrevista al señor Sebastián Huamán Panez, se puede resumir que:

La intención pedagógica en la canción Yo soy de Junín, se toma como si fuera una canción dedicada a la ciudad de Junín. Como se observa en los siguientes versos: El Mantaro es mi valle, Huancayo, Jauja, Oroya y Tarma son pueblos de mi Junín. Por lo tanto, la canción expresa una forma de enseñar y aprender a interiorizar una idea equivocada de pertenencia a la provincia de Junín. 
La canción Yo soy de Junín, encierra un significado pedagógico, de identidad equivocada, habla en su composición de algunas provincias solamente, esa canción no identifica a la provincia de Junín. Como se percibe en los siguientes versos: El Mantaro es mi valle, Huancayo, Jauja, Oroya y Tarma son pueblos de mi Junín. Por lo tanto, la canción expresa una forma de enseñar y aprender a adoptar una identidad ajena a la provincia de Junín.

La función pedagógica que cumple la canción Yo soy de Junín, durante el tiempo trascurrido el autor no ha podido corregir la estrofa que menciona al departamento de Junín. Como se percibe en los siguientes versos: $E l$ Mantaro es mi valle, Huancayo, Jauja, Oroya y Tarma son pueblos de mi Junín. Por lo tanto, la canción expresa una forma de enseñar y aprender equivocadamente las fronteras territoriales en la provincia de Junín.

Sobre las condiciones pedagógicas que cumple la canción Yo soy de Junín, nos ubicaremos en el tiempo pasado, donde nadie durante el tiempo desde su creación objetó ni observó las inconsistencias de sus letras. Como se percibe en el siguiente verso: Huancayo, Jauja, Oroya y Tarma son pueblos de mi Junín. Por lo tanto, en la canción expresa una forma de enseñar y aprender a corregir relatos cantados de la provincia de Junín.

\section{Interpretación interlineal del investigador}

Es la intención de enseñar a identificarse con el presente y futuro junino de nacimiento hasta la muerte. Mostrando sentimiento de pertenencia al valle del Mantaro (Huancayo, Jauja, Oroya y Tarma), libre de contaminación y el contacto directo con la naturaleza, para comunicar que es mejor habitar en Junín. Como se puede apreciar en los versos: Yo soy de Junín por vida. El Mantaro es mi valle. Huancayo, Jauja, Oroya y Tarma son pueblos de mi Junín. En esta tierra en donde se vive contento y muy feliz. Orgulloso vivo por eso porque mi terruño es Junín. En Junín se vive dichoso bajo el aire libre y puro. Muestra la reseña de la canción y a la vez hermosea a su tierra como su musa. Enseña sobre la identificación por satisfacción del habitante junino excepto de las provincias de Junín, Chupaca, Yauli, Jauja, Concepción, Chanchamayo y Satipo pues no las menciona.

Hay una intención pedagógica de enseñar que Bolívar lucho en Junín. Un héroe luchador y que el escenario donde lucha se engrandece con tal suceso. Como se puede apreciar en los versos: En Junín luchó Bolívar. Orgulloso vivo por eso porque mi terruño es Junín. Para demostrar orgullo y agradecimiento.

Enseñanza pedagógica de los valores de contexto de la canción en estudio, comunica su identidad o su deseo con mensajes de machismo, virilidad, infidelidad, enamoradora y viveza con la advertencia cariñosa y lúdica. Como se puede apreciar en los versos: Ladroncito soy de amores. No me importa amor de extraños. Cuidado negra que yo me lleve robando tu corazón. Advierte a los extraños de su superioridad enamoradora e indica que las mujeres de su tierra son mejores, aunque por debajo del hombre pues negra hace referencia al esclavismo.

Significa que el marco de referencia de la canción es Junín. Delimita geográficamente la reseña del nacimiento de su canción y describe a Junín como productiva, hermosa, tierra de luchas, limpia y sin contaminación. Como se puede apreciar en los versos: En Junín nació mi verso. En Junín luchó Bolívar. En esta tierra en donde se vive contento y muy feliz. Orgulloso vivo por eso porque mi terruño es Junín. En Junín se vive dichoso bajo el aire libre y puro. Que llena de orgullo a sus pobladores.

La canción describe al autor. Es enamorador y le gusta su tierra, le interesa preservar su raza, tiene en su poder el corazón de una dama y que no va a poder olvidarlo pues es su esclava. Ladroncito soy de amores. No me importa amor de extraños. Cuidado negra que yo me lleve robando tu corazón. Orgulloso vivo por eso porque mi terruño es Junín. Para demostrar su forma de inspiración.

Hay una función de sublimación a su tierra. Mediante el chauvinismo territorial, la pertenencia, la relación entre Junín y el libertador Bolívar. Como se puede apreciar en los versos: Yo soy de Junín por vida. El Mantaro es mi valle. En Junín luchó Bolívar. En esta tierra en donde se vive contento y muy feliz. Orgulloso vivo por eso porque mi terruño es Junin. En Junín se vive dichoso bajo el aire libre y puro. Para transferir el sentir a los pobladores juninos.

El autor tiene una tendencia impulsiva o instintiva al enamoramiento. Identificación del narcicismo por su cualidad poco moral, aunque hay un mecanismo de defensa o resistencia contra los extraños y sus costumbres. 
Como se puede apreciar en los versos: Ladroncito soy de amores. No me importa amor de extraños. Cuidado negra que yo me lleve robando tu corazón. Para alimentar su ego y su yo o superyó junino.

Condicionamiento del lugar de nacimiento. Hay un refuerzo positivo a la vivencia junina, engrandece a su tierra por su aire sin contaminación e información histórica y patriótica; el autor no migraría como los demás. Como se puede apreciar en los versos: Yo soy de Junín por vida. En Junín nació mi verso. En Junín luchó Bolívar. En esta tierra en donde se vive contento y muy feliz. Orgulloso vivo por eso porque mi terruño es Junín. En Junín se vive dichoso bajo el aire libre y puro. Se siente bien y hasta compone su canción para lograr pertenencia y compromiso.

Respuesta al ingreso de nuevas personas a su tierra. El gobierno de Leguía tenía una política de colonización por "mejorar la raza" y el autor no está de acuerdo a ello y muestra machismo, galantería y promiscuidad con desensibilización para el otro, de igual modo el control con una conducta operante sobre la mujer a la que sarcástica o cariñosamente la llama negra. Como se puede apreciar en los versos: Ladroncito soy de amores. No me importa amor de extraños. Cuidado negra que yo me lleve robando tu corazón. Su expresión se oye en canciones y estilos como la tunantada o el Santiago como parte de la evolución de las canciones andinas hasta la actualidad.

\section{Categorización}

Intención de transmitir sentimientos e identidad presente y futuro a su tierra. Con amor, valorando, orgullo y agradecimiento por la satisfacción de ser libre de contaminación y el contacto directo con la naturaleza. Como se puede apreciar en los versos: Yo soy de Junín por vida. Orgulloso vivo por eso porque mi terruño es Junín. En Junín se vive dichoso bajo el aire libre y puro. Para preservar su identidad, con sentimiento de pertenencia.

Intención de educar a sus ciudadanos y a todo peruano. Sobre la Batalla de Junín y Bolívar, los valores de una cultura equivocada como el machismo, virilidad, infidelidad, enamorador, viveza, enfoque al esclavismo. Como se puede apreciar en los versos: El Mantaro es mi valle. Huancayo, Jauja, Oroya y Tarma son pueblos de mi Junín. En Junín luchó Bolívar. Cuidado negra que yo me lleve robando tu corazón. Para demostrarla superioridad de hombre y mujeres de su tierra.

Significado de una identidad provincial equivocada. Liderazgo inapropiado de Bolívar en la Gloriosa Batalla de Junín y comprender hechos, historia; inconsistencias al no nombrar a todas las provincias. Como se puede apreciar en los versos: Yo soy de Junín por vida. El Mantaro es mi valle. Huancayo, Jauja, Oroya y Tarma son pueblos de mi Junín. En Junín nació mi verso. En Junín luchó Bolívar. Para crear una irreal identidad provincial ajena a la provincia de Junín.

Se da un significado al autor con Junín como el marco de referencia. Enamorador que le gusta su tierra, le interesa preservar su raza y su tierra productiva, hermosa, tierra de lucha, limpia y sin contaminación. Como se puede apreciar en los versos: Yo soy de Junín por vida. El Mantaro es mi valle. Huancayo, Jauja, Oroya y Tarma son pueblos de mi Junín. En Junín nació mi verso. En Junín luchó Bolívar. En esta tierra en donde se vive contento y muy feliz. Orgulloso vivo por eso porque mi terruño es Junín. En Junín se vive dichoso bajo el aire libre y puro. Con el propósito de reseñar su canción.

Función de Sublimación a su tierra. Con sentido de pertenencia, chauvinismo territorial, bienestar, la relación Junín - Bolívar. Como se puede apreciar en los versos: Yo soy de Junín por vida. El Mantaro es mi valle. En Junín nació mi verso. En Junín luchó Bolívar. En esta tierra en donde se vive contento y muy feliz. Orgulloso vivo por eso porque mi terruño es Junín. En Junín se vive dichoso bajo el aire libre y puro. Para transferir el sentimiento a los juninos.

Función de Difusión y fortalecimiento de la identidad del autor. Expresado en emociones, decepción, machismo, violencia, venganza, carencia de respeto a las parejas formadas y al uso de la fuerza, tendencia impulsiva o instintiva al enamoramiento, narcicismo, cualidad poco moral, ego y su yo o superyó junino. Como se puede apreciar en los versos: Ladroncito soy de amores. No me importa amor de extraños. Cuidado negra que yo me lleve robando tu corazón. Con el fin de crear un mecanismo de defensa o resistencia contra los extraños y sus costumbres. 
Condicionamiento del lugar de nacimiento. Lo lleva al conformismo y quedarse en su tierra, pero desarrolla en el arte y el canto su creatividad, compromiso y expresión libre aunque con inconsistencias de sus letras da un refuerzo positivo a la vivencia junina al engrandecerla por su aire, sin contaminación e información histórica y patriótica. Como se puede apreciar en los versos: Yo soy de Junín por vida. El Mantaro es mi valle. Huancayo, Jauja, Oroya y Tarma son pueblos de mi Junín. En Junín nació mi verso. En Junín luchó Bolívar. En esta tierra en donde se vive contento y muy feliz. Orgulloso vivo por eso porque mi terruño es Junín. En Junín se vive dichoso bajo el aire libre y puro. Consecuencia son su Identidad cultural provincial y rechazo a la migración.

El condicionamiento histórico contra las políticas de "mejorarla raza". Mediante el machismo, galantería y promiscuidad con desensibilización para el otro, de igual modo el control con una conducta operante, sarcástica o cariñosa a la mujer como la tunantada, y el Santiago. Como se puede apreciar en los versos: Ladroncito soy de amores. No me importa amor de extraños. Cuidado negra que yo me lleve robando tu corazón. Consecuencias son la evolución de las canciones andinas.

\section{Materiales y métodos}

Se utilizó el método hermenéutico, correspondiente a la investigación cualitativa para el análisis de la canción. Con la colaboración de cuatro cantautores profesionales de música juninense y la interpretación del investigador los pasos que se siguieron para la investigación fueron: el esclarecimiento de los presupuestos, etapa descriptiva (técnica de entrevista coloquial o dialógica) grabada y analizada, luego la descripción hermenéutica interlineal y la etapa estructural o categorización (Martínez, 2004). Para evitarla proyección de nuestro mundo interno.

\section{Discusión de resultados}

El autor tuvo una intención pedagógica de transmitir sentimientos e identidad presente y futuro a su tierra además educar a sus ciudadanos y a todo peruano. Aunque con inconsistencias de separar a los distritos de Junín como Ulcumayo, Ondores, Carhuamayo y al mismo Junín. Para el orgullo juninense. De alguna forma la posición liberal, democrática y reformista española junto a las políticas peruanas en la región Junín lo corroboraron (Alberto, 2011; Contreras, 2009; Leguía, 1930).

La canción da Significado de una identidad provincial equivocada y relaciona al autor con Junín como su marco de referencia. Por su separación a los distritos de Junín como Ulcumayo, Ondores, Carhuamayo y al mismo Junín y la idea de sometimiento a la mujer como en la música de Santiago o tunantada. Que fueron creadas para desahogarse o salir de rutinas.

Función de Sublimación a su tierra y de difusión y fortalecimiento de la identidad del autor. Comprendiendo las vivencias emocionales y mezclando una serie de contravalores machista, promiscuidad y galantería al someter a la mujer principalmente con objeto de someterla (Pineau \& Mora, 2011). Para reafirmar sus propiedades de nacimiento, historia y patriotismo (Eugenio Llactahuaman, 2019).

Condicionamiento del lugar de nacimiento y el condicionamiento histórico contra las políticas de "mejorar la raza". Las canciones serranas fueron construidas y transformadas en procesos complejos y multidisciplinarios teniendo como referentes los hechos históricos y culturales. Para la manifestación de su cultura.

\section{Conclusiones}

Subyace una posible intención pedagógica del autor de la canción Yo soy de Junín, la de transmitir los sentimientos e identidad presente y futuro a su tierra además de educar a sus ciudadanos y a todo peruano. Con el significado de una identidad provincial equivocada y relación del autor con Junín como su marco de referencia. Cumpliendo la función de sublimación a su tierra, de difusión y fortalecimiento de la identidad del autor. Por el condicionamiento del lugar de nacimiento e histórico contra las políticas de "mejorar la raza". 


\section{Referencias Bibliográficas}

Alberto, L. (2011). La guerra civil española y la polarización ideológica y política: la Argentina 1936- 1946. Conicet, $38(2), 17-37$.

Cerrón, W. (2019). La investigación cualitativa en educación. Horizonte de La Ciencia, 9(17), 159- 165.

Contreras, C. (2009). La crisis mundial de 1929 y la economía peruana. Crisis Internacional: Impactos y Respuestas de Política Económica en el Perú la, 21-55. http://repositorio.pucp.edu.pe/index/bitstream/ handle/123456789/46603/parte1.pdf?sequen ce=3\&isAllowed=y

Eugenio Llactahuaman. (2019). La música huancaína: Tunantada, Santiago y Huaylarsh. Escuela Nacional Superior de Folklore José María Arguedas.

Leguía, A. B. (1930). Mensaje del presidente del Perú, Augusto Bernardino Leguía Salcedo, ante el Congreso Nacional, el 28 de julio de 1930. Presidencia de La República, October 2013, 1-224.

https://doi.org/10.1017/CBO9781107415324.004

Martínez, M. (2004). Ciencia y arte en la metodología cualitativa (Editorial Trillas (ed.); 1st ed.).

Pineau, F., \& Mora, A. (2011). La reconstrucción de las identidades en la música popular andina en Perú: un campo de disputa y negociación cultural. Ensayos Pedagógicos, 6(1), 67-81. 